\title{
Evaluating aquaponic crops in a freshwater flow-through fish culture system
}

\author{
Karen M. Buzby ${ }^{1}$, Nicole L. Waterland ${ }^{2}$, Kenneth J. Semmens ${ }^{3 a}$ and Lian-Shin Lin ${ }^{1}$ \\ ${ }^{1}$ Department of Civil and Environmental Engineering, West Virginia University, Morgantown, \\ WV, ${ }^{2}$ Division of Plant and Soil Science, West Virginia University, Morgantown, WV, \\ ${ }^{3}$ Division of Animal and Nutritional Sciences, West Virginia University, Morgantown, WV.
}

Corresponding author:

Karen M. Buzby, Department of Civil and Environmental Engineering, P.O. Box 6103, West Virginia University, Morgantown, WV 26506. (P) 304-293-9923, (F) 304-293-7109, email:kmbuzby@mail.wvu.edu

${ }^{a}$ Current address: Aquaculture Research Center, Kentucky State University, Frankfort, KY 


\begin{abstract}
:
This study examined the establishment and growth performance of 34 food crops grown in a cool, low nutrient aquaponic system. Process water from a spring-fed flow-through trout raceway, with an average fish biomass of $3630 \mathrm{~kg}$, was used as the water and nutrient source for the plant growing operation. Process water temperature entering the plant growing channels was $13{ }^{\circ} \mathrm{C}$ with average concentrations of $0.35,0.34$ and $0.19 \mathrm{mg} \cdot \mathrm{L}^{-1}$ for ammonium, nitrate, and phosphate, respectively. Crop types included lettuce, Asian greens, mustards, other greens, vegetables and herbs. Stand establishment (percent filled cells) and harvest and individual biomass were evaluated under three treatments; low flow $(18.9 \mathrm{~L} / \mathrm{min})$, high flow $(75.7 \mathrm{~L} / \mathrm{min})$ and an amended high flow treatment. The amended high flow treatment consisted of vermiculite planting media amended with composted fish waste and was placed in a channel receiving high flow. These treatments represented a gradient of nutrient availability with low flow receiving the fewest and the amended high flow treatment receiving the most nutrients. Due to space constraints cultivars were sown in two sets. Cultivars in set two were sown as space was made available when cultivars from set one were harvested. Stand establishment was greater than $80 \%$ for most cultivars under all treatments. However, the herbs sage, garlic chive, and lovage had poor stand establishment as did the vegetables Swiss chard and beets, which were sown late in the study. For most cultivars, stand establishment was not significantly different among treatments. The majority of cultivars attained the lowest biomass on the low flow treatment. Notable exceptions were cilantro, parsley, and minutina. Eight cultivars, including kohlrabi and the bibb lettuce 'Rex', grew best on the high flow treatment. The remaining 21 cultivars realized the greatest biomass on the amended treatment although in many cases the increase in biomass was minor. Additionally, for some cultivars, significant increases in stand establishment offset decreases in growth. Minimal improvements in water quality were observed, probably as a result of nutrient mobilization from accumulated solids within the aquaponic channels.
\end{abstract}

Keywords: aquaponics, flow-through, crop production, nutrients, trout 


\section{Introduction}

Within any agricultural operation, it is important to choose crops that will produce well within the constraints of the growing environment. Aquaponics, a blending of aquaculture and hydroponics, creates a unique environment where production has been quantified for few crops. In an aquaponic system, process water exiting the fish culturing operations is used as a water and nutrient source for plant crops. Physical and chemical properties of the effluent (temperature, nutrient concentrations, etc.) are dependent on the type and quantity of fish being grown and may not be suitable for all crops.

An aquaponic system can benefit the aquaculture operation by improving the quality of recirculated water (Rakocy et al., 2006) or by reducing costs associated with treating effluent from flow-through raceways. The hydroponic operation is benefited through the reduction of fertilizer inputs and labor or facilities needed to maintain adequate moisture levels. The linking of fish culture with plant culture allows both operations to reduce inputs and makes the enterprise more sustainable (Tyson et al., 2011). In addition, incorporation of aquaponics into traditional aquaculture provides growers with an additional revenue source.

The quality of effluent generated by aquaponic fish culture operations (i.e., temperature, nutrient concentrations, dissolved oxygen concentrations) can have large impacts on which crops could be grown as well as production rates. Typical aquaponic systems culture fish that require warm temperatures $\left(25-27^{\circ} \mathrm{C}\right)$ such as tilapia (Al-Hafedh et al., 2008, Rakocy et al., 2006, Savidov et al., 2007), although Murray cod (Lennard and Leonard, 2006) and African catfish (Endut et al., 2009) have also been used. In addition, most aquaponic systems culture fish in a recirculating system. A benefit claimed by these systems is that nutrient concentrations approximate hydroponic systems (Rakocy et al., 2006). Reported soluble nutrient concentrations vary widely with nitrate concentrations ranging from 21 to $62 \mathrm{mg} \cdot \mathrm{L}^{-1}$ (Al-Hafedh et al., 2008, Savidov et al., 2007) and phosphate concentrations ranging from 0.7 to $10.3 \mathrm{mg} \cdot \mathrm{L}^{-1}$ (Adler et al., 2003, AlHafedh et al., 2008). A wide variety of crops have been grown in these aquaponics systems including basil (Adler et al., 2003), lettuce and tomato (Rakocy et al., 1993), cucumber and herbs (Savidov et al., 2007).

Flow-through fish culture systems that are generally used to culture fish such as trout and Arctic char operate at cooler water temperatures $\left(12-15^{\circ} \mathrm{C}\right)$. Additionally, since there is less contact time between the water and the fish, nutrient concentrations are commonly 10 to 100 fold lower than those found in in effluent from recirculating fish culture (Buzby and Lin 2014). Previous studies have demonstrated that, despite the water quality differences between a typical aquaponic system (warm, high nutrient) and typical trout effluent (cool, low nutrient), aquaponic production is practical in a flow-through system (Palmatory et al., 2010). Moreover, reductions in soluble nutrient concentrations were attained (Buzby et al., 2010).

Since the low temperature, low nutrient conditions in flow-through trout raceway effluent are different from those typically used for aquaponics, a study evaluating potential crops was deemed necessary. The aim of this study was to grow as many cool season crops as feasible to determine which grew well in this system. In addition, the effect of low nutrient concentrations was addressed by growing the crops under three treatments with varying nutrient availability. The treatments consisted of low flow with vermiculite media, high flow with vermiculite media, and a high flow treatment with vermiculite amended with $50 \%$ composted fish waste (uneaten 
food and feces). As all of the nutrients were derived from the effluent, the low and high flow treatments were equivalent to low and high nutrient availability. The amended treatment supplied additional nutrients from the decomposition of composted fish waste. We used stand establishment and harvest and individual biomass as parameters to evaluate the performance of the cultivars.

\section{Methods}

Experiments were conducted in a $7.9 \mathrm{~m}$ x $14.6 \mathrm{~m}$ x $3.7 \mathrm{~m}$ tall high tunnel covered in 6 mil $(0.15$ $\mathrm{mm}$ thick) clear greenhouse plastic located in eastern West Virginia, USA. Ventilation in the high tunnel was provided by rolling up the side walls approximately $1.4 \mathrm{~m}$ and removing the end walls. The end and side walls were closed in mid-October. A HOBO pendant temperature logger (Onset Computer Corp., Pocasset, MA), placed in to a $10 \mathrm{~cm}$ diameter white PVC pipe for shading and located at plant level, was used to monitor air temperature inside the high tunnel (Figure 1). Technical difficulties precluded acquisition of a complete temperature record for the entire length of the study. The record was supplemented with maximum and minimum air temperatures recorded at a NOAA observation point within $450 \mathrm{~m}$ of the high tunnel. Even with the side and end walls open, maximum temperatures were higher in the high tunnel, although minimum temperatures were similar. When the side and end walls were closed, maximum temperatures inside the high tunnel were substantially higher than outside temperatures while minimum temperatures were moderated somewhat.

\subsection{Growth conditions}

Three plant growing channels $(2.7 \mathrm{~m} \times 13.7 \mathrm{~m})$ constructed of dry stacked concrete block on a fine gravel base were covered with a white Dura-skrim ${ }^{\circledR}$ R20WW (Raven Industries) liner. The block was stacked such that the channel was $30.5 \mathrm{~cm}$ deep. Effluent from rainbow trout (Oncorhynchus mykiss) reared in a flow-through system in a nearby building was used as the sole water and nutrient source in this study. The trout effluent was pumped to the high tunnel and distributed via a PVC manifold. Flow into each channel was independently controlled via a ball valve. Influent velocity was monitored biweekly and adjusted if necessary. Water depth was maintained at $23 \mathrm{~cm}$ with a standpipe drain.

There were three treatments in the study; low flow $(18.9 \mathrm{~L} / \mathrm{min})$, high flow $(75.7 \mathrm{~L} / \mathrm{min})$ and an amended high flow treatment. In the amended treatment, the system was operated at high flow $(75.7 \mathrm{~L} / \mathrm{min})$ and composted fish waste was added at a 1:1 ratio (v/v) to the standard vermiculite culture medium. Each channel contained a single treatment (Figure 2). We evaluated 34 cultivars which can grouped into the following categories: lettuce (Latuca sativa 'Rex' and 'Rhazes'), Asian greens ((Brassica juncea 'Red Rain'), mizuna (Brassica rapa var. japonica), tatsoi (Brassica rapa var. narinosa), Tokyo bekana (Brassica rapa var. chinensis), vitamin green (Brassica rapa var. narinosa), and shungiku (Glebionis coronaria)), mustard greens (Brassica rapa japonica group 'Suehihung No. 2', Brassica juncea 'Southern Giant Curled' and 'Red Splendor'), other greens (minutina (Plantago coronopus), cresses (Lepidium sativum 'Persian Cress' and 'Wrinkled Crinkled Cress'), arugula (Eruca sativa Arugula, and 'Surrey'), wild arugula (Diplotaxis tenuifolia 'Sylvetta'), and Italian dandelion (Cichorium intybus 'Clio'), vegetables (kohlabi (Brassica oleracea gongylodes group 'Winner'), Swiss chard (Beta vulgaris 'Peppermint'), and beets (Beta vulgaris 'Bull's Blood' and 'Early Wonder Tall Top')) and herbs 
(sorrel (Rumex acetosa), green shiso (Perilla frutesce), cilantro (Coriandrum sativum 'Santo'), Italian oregano (Origanum x majoricum), lovage (Levisticum officinale), chive (Allium tuberosum 'Fine Leaf'), parsley (Petroselinum crispum 'Darki'), garlic chive (Allium tuberosum 'Nira'), salad burnet (Sanguisorba minor), winter savory (Satureja montana), sage (Salvia officinalis 'Extrakta') and rosemary (Rosemarinus officinalis)). All seeds were purchased from Johnny's Selected Seeds, Winslow, ME.

Plants were grown in styrofoam Speedling (Speedling, Inc., Ruskin, FL) trays to which vermiculite or the composted fish waste/vermiculite mixture was added as a growing medium. Seeds were sown directly into the Speedling trays. Most cultivars were sown into 128-cell trays. However, crops that were thought to be more marketable at a larger size or matured to a larger size (head lettuce, kohlrabi, cilantro, Swiss chard, beets) were sown into a 32-cell tray. The 128cell trays were sown using a vacuum seeder, while the 32-cell trays were sown by hand. The Speedling trays were placed 4 trays across each channel such that each row contained one cultivar as depicted in Figure 2. Cultivars were placed in the same order and at the same distance from the influent across all channels. Cultivars sown into 32-cell trays were placed at the beginning of the channel nearest the influent.

The cultivars were evaluated in 2 sets of experiments due to space constraints. All cultivars in set one were sown on 7/18/2013. As space became available, through the harvest of cultivars in set one, cultivars in set two were sown. Sowing dates for cultivars in set two ranged over 45 days (8/26/2013 to 10/10/2013). In all cases, an individual cultivar was sown across all treatments on the same date. Additionally, where there were multiple cultivars within a group, such as mustard greens, the cultivars within a group were sown on the same date to facilitate comparison. Exceptions include the herbs which were sown in both sets and 2 different lettuce cultivars that were sown one to each set. Newly sown 128-cell trays were placed directly downstream of any 32-cell trays present in the channel such that the most recently sown trays were closest to the influent of the channel and cultivars that had been in the system the longest were furthest from the influent.

Stand establishment (percent filled cells) was assessed on each tray two to four weeks after sowing. A filled cell contained at least one germinated seedling. Cells were thinned to two seedlings per cell if necessary. Most cultivars were harvested when they reached harvestable size based on horticultural information and product size in grocery stores. Exceptions to this included shiso, oregano, winter savory, and rosemary. Shiso and oregano were sown in the first set and were harvested at below market size. Shiso leaves are typically harvested multiple times. In this case, we harvested the whole plant so that biomass could be more readily compared with other cultivars. Winter savory and rosemary, sown in the second set, were also harvested below market size as the growing season was ending and they had stopped growing.

Most cultivars were harvested using an electric fillet knife that cut the plant stems cleanly approximately $1 \mathrm{~cm}$ above the surface of the tray. In cultivars where the stem was too tough for the fillet knife to cut cleanly (e.g., shiso, kohlrabi), scissors or a knife was used. Each tray was harvested separately and a fresh weight per tray was determined. Individual biomass at the time of harvest was calculated by dividing harvest biomass per tray by the number of filled cells.

\subsection{Water Chemistry}


Changes in water quality between the beginning and end of the channel were quantified every two weeks by taking water samples at the influent and at the end of each channel. Samples were immediately placed on ice until they were transported to the lab where they were held at $4{ }^{\circ} \mathrm{C}$. The samples were analyzed according to methods delineated by APHA (1995) for total suspended solids (TSS) $(2540 \mathrm{D})$, ammonium $\left(4500-\mathrm{NH}_{3}\right.$ phenate method), nitrate $\left(4110-\mathrm{NO}_{3}{ }^{-}\right.$ ion chromatography with direct conductivity detection) and phosphate (4500-P ascorbic acid method).

\subsection{Statistical analysis}

Stand establishment and harvest and individual biomass data were analyzed with one way analysis of variance (ANOVA). Data were transformed as necessary to ensure homogeneity of variance. Tukey's HSD post-hoc tests were conducted where significant differences between means were detected. Water quality data were also analyzed with one-way ANOVA with Tukey's HSD post-hoc tests. We evaluated whether influent and effluent nutrient concentrations varied among treatments. Within a treatment, t-tests were used to determine if there were significant differences in soluble nutrient concentrations or TSS between the influent and effluent.

\section{Results}

\subsection{Stand Establishment}

Overall, stand establishment was high with an average of $74 \%$ across all cultivars and treatments (Figure 3). Within set one, minutina had the highest stand establishment with greater than $95 \%$ filled cells. The Asian greens, with the exception of shungiku, as well as many of the herbs, also had high establishment. The bibb lettuce 'Rex' averaged $87 \%$ filled cells while kohlrabi had a lower stand establishment of 76\%. Poor stand establishment was observed in the herbs lovage $(35 \%)$ and garlic chive $(27 \%)$.

Stand establishment was more variable in set two. The butterhead lettuce 'Rhazes' and all of the greens, with the exception of Italian dandelion, had very high stand establishment. In contrast, the beets and Swiss chard, which were sown late in the period, had low stand establishment. The herbs in set two had lower stand establishment than in set one and stand establishment was poor in sage.

In most cultivars, stand establishment was not significantly different among treatments. However in the Asian greens, Red Rain, mizuna, Tokyo bekana, and arugula stand establishment was significantly higher in the amended treatment than the low flow but not high flow treatment. In chives, the mustards southern giant curled and suehlihung No. 2, and Swiss chard, stand establishment was significantly higher in the amended treatment than high flow but not low flow treatment. Finally, stand establishment was significantly higher in the amended treatment than both high and low flow in vitamin green, the herbs parsley, garlic chive, salad burnet and sage, and both beet cultivars.

\subsection{Harvest Biomass}

The cultivars evaluated varied widely in both time to harvest as well as harvest biomass (Table 
1). Within set one, the Asian greens grew the fastest and were ready to harvest within 35-42 days. Therefore they were ready to harvest sooner than the other cultivars. The lettuce and other greens grew slightly slower but were still ready to harvest within 49 days. Kohlrabi was ready to harvest after 70 days. The herbs sorrel and green shiso also grew quickly and were ready to harvest after 42- 49 days while the remainder of the herbs grew slowly with days to harvest exceeding 70 days.

Many of the cultivars in set two also grew quickly despite being sown in late summer to fall. The cresses were ready to harvest 36 days after sowing, the mustard greens were ready to harvest after 49 days and the arugula cultivars were harvested after 56 days. However, all of the herbs in set two grew slowly and were harvested $73-81$ days after sowing as they had stopped growing.

\section{Lettuce}

The two lettuce cultivars, 'Rex' and 'Rhazes' responded differently to the treatments. Harvest and individual biomass (Figure 4) in 'Rex' was greatest in the high flow treatment and was significantly less in the low flow treatment $(\mathrm{p}=0.02)$. There were no significant differences between the amended treatment and either high or low flow treatments. Conversely, in the butterhead cultivar 'Rhazes', harvest and individual biomass was significantly greater in the amended treatment than in either low or high flow treatments $(\mathrm{p}=0.02)$.

\section{Asian Greens}

Individual and harvest biomass in all of the Asian greens was significantly lower in the low flow treatment. Mizuna was the only Asian green where there were significant differences in individual biomass between the amended and high flow treatments. Red Rain, mizuna, vitamin green and shungiku had significant differences in harvest biomass among treatments. For Red Rain and mizuna the high flow treatment produced the greatest biomass while for vitamin green and shungiku the amended treatment was the most productive. There was no significant difference between the high flow and amended treatments for Tokyo bekana and tatsoi. Tokyo bekana was the most productive Asian green followed by tatsoi and vitamin green.

\section{Mustard Greens}

All of the mustard greens were significantly less productive at low flow than in the other treatments $(\mathrm{p}<0.001)$. Both 'Suehlihung No. 2' and 'Southern Giant Curled' were significantly more productive on both a harvest and individual biomass basis when grown on the amended treatment. 'Suehlihung No. 2' was the most productive mustard green.

\section{Other Greens}

Minutina was the only non-Asian green grown in set one. It was more productive than any of the Asian greens. There were no significant differences in harvest or individual biomass among treatments. Three arugula cultivars, two cresses and an Italian dandelion were grown in set two. 'Arugula' was most productive and substantially outperformed the other cultivars. Each arugula cultivar responded differently to the three treatments. 'Arugula' had low harvest biomass at low flow with a 10-fold increase at high flow and a further increase in the amended treatment. Differences among all treatments were significant $(\mathrm{p}=0.007)$. Individual biomass in the low flow treatment was significantly lower than the other treatments, however differences between the high flow and the amended treatment were not. 
'Surrey' had low individual and harvest biomass in the low flow treatment with no significant differences between the high flow and amended treatments. 'Sylvetta' performed poorly compared with the other arugulas; individual and harvest biomass in the high flow treatment was significantly greater than in the other treatments. Both cresses attained significantly greater biomass under the amended treatment, with 'Persian Cress' outperforming the 'Wrinkled Crinkled Cress'. Italian dandelion grew more slowly than the other greens with no significant difference between low and high flow but a greater than 10-fold increase under the amended treatment. Differences were significant in both harvest $(\mathrm{p}<0.001)$ and individual biomass $(\mathrm{p}<0.001)$.

\section{Vegetables}

Kohlrabi was the only vegetable cultivar grown in set one. While it took longer to reach harvestable size than most of the other cultivars in the set, it attained the greatest biomass. Production was significantly greater under high flow as compared with the other treatments $(\mathrm{p}=0.002)$. However, individual biomass was not significantly different among treatments $(\mathrm{p}=0.10)$. None of the vegetables in set two grew well. There were no significant differences in production among treatments in the chard. In the beets however, both varieties had higher production under the amended treatment. Harvest biomass in early wonder tall top was almost twice the harvest biomass than that of bull's blood.

\section{Herbs}

Harvest biomass varied widely among herb cultivars. Within set one, cilantro was the most productive. There were no significant differences among treatments for cilantro, parsley and oregano due to high variability in biomass between trays within the same treatment. In contrast, green shiso and chive had significantly greater individual and harvest biomass in the amended treatment. Sorrel had significantly less harvest biomass in the low flow treatment than the high flow but not amended treatment. In lovage, there were no significant differences in individual biomass while harvest biomass was significantly less in the amended treatment.

Within set two, salad burnet had considerably greater biomass than the other cultivars. There were no significant differences among treatments in harvest $(\mathrm{p}=0.07)$ or individual biomass $(\mathrm{p}=0.07)$ due to high variability between trays. In both winter savory and rosemary, harvest and individual biomass was greater in the amended treatment. Overall however, biomass was low for both cultivars. Harvest biomass was not evaluated for garlic chive or sage due to low stand establishment.

\subsection{Water Chemistry}

Soluble nutrient concentrations were low over the course of the experiment with average influent concentrations of $0.35 \pm 0.03,0.34 \pm 0.08$, and $0.19 \pm 0.02 \mathrm{mg} \cdot \mathrm{L}^{-1}$ for ammonium, nitrate, and phosphate, respectively (Figure 5). There was no significant difference in influent concentration among treatments $\left(\mathrm{p}=0.99,0.68\right.$, and 0.67 for $\mathrm{NH}_{4}{ }^{+}, \mathrm{NO}_{3}{ }^{-}$, and $\mathrm{PO}_{4}{ }^{2-}$, respectively).

Ammonium concentrations were significantly reduced at the end of the channel in the low flow treatment $(\mathrm{p}=0.03)$ but were little changed in the high flow $(\mathrm{p}=0.54)$ and amended $(\mathrm{p}=0.54)$ treatments. Effluent nitrate concentrations in the low flow channel were slightly reduced from the influent, however nitrate concentrations in both the high flow and amended channels increased to 0.56 and $0.52 \mathrm{mg} \cdot \mathrm{L}^{-1}$, respectively. There was no significant difference in nitrate concentration between the influent and the outlet $(\mathrm{p}=0.33,0.96$, and 0.72 for low flow, high flow, 
and amended treatments, respectively). Phosphate concentrations followed a similar pattern with a slight reduction in concentration for the low flow channel and increases in both the high flow and amended channels. There was no significant difference in concentration between influent and the outlet for any treatment $(\mathrm{p}=0.12,0.32$, and 1.00 for low flow, high flow, and amended treatments, respectively). Differences in effluent concentration among treatments were not significantly different for any of the soluble nutrients $\left(\left(\mathrm{p}=0.18,0.72\right.\right.$, and 0.13 for $\mathrm{NH}_{4}{ }^{+}, \mathrm{NO}_{3}{ }^{-}$, and $\mathrm{PO}_{4}{ }^{2-}$, respectively).

Unlike the soluble nutrient concentrations, there were significant differences among treatments in the behavior of TSS. There were no significant differences in influent TSS concentration $(\mathrm{p}=$ 0.76). Effluent TSS concentration was significantly lower than the influent in the low flow channel $(p=0.02)$. In the high flow and amended treatments, effluent TSS concentration was lower than the influent, however differences were not significant ( $p=0.35$ and 0.16 , respectively), perhaps due to high variability.

\section{Discussion}

This study evaluated stand establishment and growth performance of 34 cultivars grown in an aquaponic system under three treatment regimes. The cultivars chosen consisted of cool season crops that could be harvested relatively quickly. Cool season crops grow well in our cool water aquaponic system while warm season crops are less reliable (Porter et al., 2008). The three treatments manipulated nutrient availability by varying influent velocity and growing medium amendments. The high flow regime received four times the volume of effluent and therefore the plants had access to four times the nutrients of the low flow treatment. The amended treatment had access to additional inputs from the composted fish waste amendment. In addition to the nutrient effects, there may have been subtle temperature differences due to the treatments. Since, in the low flow treatment, the volume of cool raceway effluent supplied to the channel was less and contact time longer, the growing medium may have been warmer due to equilibration with the warm air temperatures, especially in July and August. The amended treatment may also have been warmer as the dark fish waste would absorb solar radiation at a greater rate. An additional difference among treatments was that the incorporation of composted fish waste in the amended treatment appeared to increase water holding capacity of the planting media. This may have reduced the dissolved oxygen content of the planting media which would influence both stand establishment and growth.

\subsection{Stand establishment}

In general, stand establishment was high. Nevertheless, two cultivars, garlic chive and sage, had such poor stand establishment that they were removed from the experiment. Growth of these cultivars would need to be evaluated with transplanted seedlings which was outside the scope of this experiment. Treatment effects on stand establishment were generally minor. However, there was a group of cultivars, including the Asian greens vitamin green and shungiku, both beet cultivars, and the herbs parsley and salad burnet, that had significantly higher stand establishment on the amended treatment. Seed germination and subsequent stand establishment will be greater if environmental conditions including moisture content, oxygen availability and temperature approach optimum conditions (Hadas, 2004). As we did not measure these parameters, it is unclear which, if any, could have affected stand establishment. 
Conversely, a few cultivars, including the bibb lettuce 'Rex' and the Italian dandelion 'Clio' had lower stand establishment on the amended treatment. The bibb lettuce 'Rex' was the only pelleted seed used in the experiment. Pelleted seed is coated with a mineral coating that may hinder germination under very moist conditions, as the coating may retain water close to the seed reducing oxygen availability (Johnny's Selected Seeds, 2014). We observed that the amended treatment appeared to be wetter than the vermiculite used in the other treatments. The interaction between the two may have reduced germination. The other lettuce cultivar 'Rhazes' was not a pelleted seed and there were no significant differences in stand establishment among treatments.

There are advantages and disadvantages to sowing seeds directly into the trays where the crops will be grown. Direct sowing allows the growers to avoid the labor involved in transplanting seedlings and avoids mortalities or reduced growth due to transplant shock. Additionally, there is no requirement for a temperature and humidity controlled area to establish seedlings. Nevertheless, conditions within the channel must meet the requirements for seed germination and establishment. Furthermore, it is unlikely that all seeds will germinate leading to unfilled cells within the trays. This can be compensated for by resowing seeds into unfilled cells. In addition, some thinning of excess plants will likely be required.

\subsection{Harvest Biomass}

Harvest biomass varied widely among cultivars. Most cultivars grew well within this cool temperature, low nutrient aquaponic system. However, the vegetables Swiss chard 'Peppermint', and both beet cultivars grew poorly and achieved low biomass when they were harvested at the end of the experiment. These three cultivars were sown late in the experiment and did not grow well under the fall conditions. Previous studies have shown Swiss chard 'Bright Lights' sown in the spring does grow well in this system (Palmatory et al., 2010). It is unclear whether the poor growth was due to environmental conditions or whether the cultivars were not suited to the system. The herbs oregano and rosemary and the arugula cultivar 'Sylvetta' also grew poorly in all three treatments. It is unlikely that environmental conditions limited growth in these three cultivars as they are usually sown in late August and it must be concluded that these cultivars were not suited to cultivation within this aquaponic system.

On the other hand, many cultivars grew well. Kohlrabi produced the greatest biomass of any cultivar tested although it required 70 days to produce a crop. The bibb lettuce 'Rex' was also productive and required only 49 days to produce a crop. Although most cultivars grew well, many took longer than the predicted number of days to reach harvestable size. For example, parsley was predicted to take 75 days to harvest, but instead it took 112 days, 'Persian Cress' was predicted to take 21 days but instead it took 36 days. Conversely, the Asian greens reached harvestable size slightly earlier than predicted.

Care needs to be taken when making comparisons between the two sets as well as within set two. Cultivars in set two were sown later than set one when day length was shorter and night time air temperatures were lower. Some of the last cultivars sown, Swiss chard and the beet cultivars, grew poorly and might have been more productive if sown earlier in the experiment. Conversely, the cresses, which were sown even later performed well. However, their growth performance may not have been as good if they had been sown earlier when air temperatures were higher. Additionally, growth performance of cultivars that were sown in set one could have 
been quite different if sown later.

Within each crop group, there were cultivars that outperformed the others in the group. They were Tokyo bekana within the Asian greens and Suehlihung No. 2 in the mustard greens. The most productive were minutina within the other greens, kohlrabi in the vegetables and cilantro in the herbs. It should be recognized that the bibb lettuce 'Rex', kohlrabi and cilantro were at the top of the channel closest to the influent and as such were exposed to the highest nutrient concentrations. These cultivars may not have attained the same biomass if they were placed further from the influent nutrient source.

The cultivars assessed in this study had variable responses to the different treatments. Cilantro, salad burnet, parsley, oregano, minutina, and Swiss chard did not exhibit treatment differences in harvest or individual biomass. For all other cultivars, biomass attained in the low flow treatment was the lowest across all treatments.

Eight cultivars, including the better performing kohlrabi and bibb lettuce 'Rex', attained the greatest biomass under the high flow treatment. This group included cultivars grown at the top, middle and bottom of the channel. As such, nutrient limitation does not appear to be a factor for these cultivars and incorporation of composted fish waste into the growing medium negatively impacted growth. The growing medium in the amended treatment appeared much wetter than the standard vermiculite which may have impacted oxygen availability to the roots within the growing medium.

The remaining 21 cultivars, including all of the mustard greens, and most of the Asian greens, other greens and herbs, grew better in the amended treatment. For some cultivars, this was due to higher nutrient availability as both harvest and individual biomass were greater when grown on the amended vermiculite. However, for many cultivars increased production was due to an increase in stand establishment which offset decreases in individual biomass. The most dramatic of these was salad burnet where stand establishment increased from an average of $30 \%$ for the low and high flow treatments to $90 \%$ in the amended treatment. This resulted in a $10 \%$ increase in harvest production despite a 50\% reduction in individual biomass as compared to the high flow treatment. In other cultivars, such as the Italian dandelion, stand establishment was poor under the amended treatment but individual biomass was considerably greater than in the other treatments leading to significantly greater harvest biomass. Understanding the interaction between both stand establishment and growth of individual plants is critical to understanding which is controlling harvest biomass.

While harvest biomass in the amended treatment was greater for many cultivars, frequently the increase in harvest biomass over the high flow treatment was minor. There may have been negative effects due to the high level of composted fish waste used that offset the growth increase due to increased nutrient availability. A cost/benefit analysis is necessary to assess whether the increased effort required to incorporate the fish waste translates into a sufficient increase in harvest biomass to be cost effective. Additional research is necessary into determining the optimum incorporation level for various crops.

\subsection{Water Quality}

It was difficult to assess nutrient removal in this experiment due to the large quantity of fish waste (feces and uneaten food) that accumulated in the channels. Total suspended solids 
concentrations averaged $1.7 \mathrm{mg} \cdot \mathrm{L}^{-1}$ at the influent. The greatest reduction in TSS concentration occurred in the low flow treatment as the lower water velocity allowed more of the particles to be deposited. These particles, consisting of fish feces and uneaten food, constituted an additional nutrient source as they decomposed in place. Despite this, effluent nutrient concentrations in the low flow treatment were lower than the other treatments although the difference was not significant.

The accumulation of solids in the bottom of the plant growing channels, while being a nutrient source, has the potential for negative effects. Decomposition of the solids can reduce oxygen availability to the plant roots as well as providing substrate for microbes to grow. Fungal mats were commonly observed. Plant roots can be fouled which may increase the potential for disease. Continuous production as well as the large size of the aquaponic channels precluded effective removal of fish waste during this study. While we did not observe any disease, the system was in operation for only four months. Systems that are in operation for longer periods would be expected to experience greater solids accumulation which may cause problems. Better removal of the fish waste from the process water entering the aquaponic channels or a system to remove waste from within the channel would reduce the potential for these negative effects. Additionally, more effective nutrient removal would be expected.

\subsection{Aquaponic Production}

The cultivars selected for this experiment included a variety of crop types. There were fast growers, such as the cresses and the Asian greens that matured quickly allowing rapid turnover of growing space but required more labor as they need to be harvested and resown. Another assemblage, consisting of the mustard greens, arugulas and lettuces did not grow as rapidly but had the potential to be harvested multiple times from one sowing. Multiple harvests from a single sowing can reduce both labor and material costs. Another major group were the herbs, which are a high value crop that can be harvested multiple times but tend to grow more slowly. Growing multiply harvested crops may result in more consistent nutrient removal over the growing season as the root system would not need to be regrown after each harvest.

Within each group were cultivars that were more productive. For example, of the 3 arugulas, 'Sylvetta' did not grow well and while 'Surrey' grew better, Arugula was substantially more productive. Within the mustard greens, Suehlihung No. 2 produced more biomass than the other 2 cultivars. 'Persian Cress' was more productive than the 'Wrinkled Crinkled Cress'. These results demonstrate the importance of testing multiple cultivars, where available, to determine which cultivar grows best within a particular system's constraints. In addition, this investigation identified cultivars that were not suited to aquaponic production under these conditions. Examples include oregano and rosemary which grew poorly under all treatments.

Many of the crops we tested took longer than predicted to reach harvestable size. There was no pattern to indicate which crops reached harvestable size within the predicted time frame and which took longer. Production rates, time to harvest, and harvestable biomass are functions of air and water temperature, light availability (day length and light intensity), and nutrient availability. Predicting production can be difficult as these variables fluctuate seasonally as well as between years.

In addition, there is the potential for more variability in water quality between aquaponic systems 
because source water is not retained. To a large extent, source water is not modified by the passage through the fish rearing operation, other than an elevation of nutrient concentrations, and therefore the effluent reflects the temperature and chemical signature of the source water. The wide variety of source waters used in aquaculture including springs, well water, lake and stream water that could potentially be used in aquaponic culture, suggests that additional trials should be completed to give a more comprehensive understanding of how well these crops might grow in aquaponic systems.

Nevertheless, this study has demonstrated that there is a wide variety of aquaponic crops that may be grown, that cultivars of the same crop may vary in productivity, and that not all cultivars perform best under elevated nutrient conditions. Aquaponic growers will need to determine what their production rates are, how they vary seasonally and how that affects competition with more traditional growing methods. 


\section{Acknowledgements:}

This study was funded by the United States Department of Agriculture Conservation Innovation Grant program under agreement 69-3A75-11-200. The authors appreciate the assistance of Gene Jacobs in the setup and maintenance of this study. 


\section{References}

Adler P.R., Summerfelt S.T., Glenn D.M., Takeda F. 2003. Mechanistic approach to phytoremediation of water. Ecol. Eng. 20, 251-264.

Al-Hafedh Y.S., Alam A., Salaheldin Beltagi M. 2008. Food production and water conservation in a recirculating aquaponic system in Saudi Arabia at different rations of fish feed to plants. J. World Aquacult. Soc. 39, 510-520.

APHA (American Public Health Administration) 2005. Standard methods for the examination of water and wastewater, $19^{\text {th }}$ edition. American Public Health Administration, Washington, D.C.

Buzby K.M., Lin L-S. 2014. Scaling aquaponic systems: balancing plant uptake with fish output. Aquacult. Eng. 63, 39-44.

Buzby K.M.., West T.P., Wei X., Semmens K.J. 2010. Nutrient removal by aquaponic crops. Paper presented at the Aquaculture America Conference, San Diego, CA, 2-5 March 2010

Endut A., Jusoh A., Ali N., Wan Nik W.N.S., Hassan A. 2009. Effect of flow rate on water quality parameters and plant growth of water spinach (Ipomoea aquatica) in an aquaponic recirculating system. Desalination and Water Treatment 5, 19-28.

Hadas A. 2004. Seedbed preparation- the soil physical environment of germinating seeds, in: Benech-Arnold R.L., Sánchez R.A. (Eds), Handbook of seedling physiology: applications to agriculture, Hawarth Press, New York, pp. 3-50.

Johnny's Selected Seeds 2014. Pelleted Seed. http://www.johnnyseeds.com/assets/information/pelleted-seed-8984.pdf Acessed 5 Dec 2014

Lennard W.A., Leonard B.V. 2006. A comparison of three different hydroponic sub-systems (gravel bed, floating and nutrient film technique) in an aquaponic test system. Aquacult. Int. 14, 539-550.

Palmatory T.K., West T.P., Buzby K.M., Wei X., Semmens K.J. 2010. Evaluation of aquaponic crop production utilizing effluent from a flow-through aquaculture raceway system. Paper presented at the Aquaculture America Conference, San Diego, CA, 2-5 March 2010

Porter J., West T.P., Buzby K.M., Semmens K.J. 2008. Evaluation of value-added marketable plant species utilizing a cold-water flow-through aquaculture system. Poster presented at the Aquaculture America Conference, Orlando, FL, 9-12 February 2009

Rakocy J.E., Hargreaves J.A., Bailey D.S. 1993. Nutrient accumulation in a recirculating aquaculture system integrated with hydroponic vegetable production. Paper presented at the American Society of Agricultural Engineers Conference, Spokane WA, 21-23 June 1993

Rakocy J.E., Masser M.P., Losordo T.M. 2006. Recirculating aquaculture tank production systems: aquaponics-integrating fish and plant culture. Southern Regional Aquaculture Center. p 1-16.

Savidov N., Hutchings E., Rakocy J.E. 2007. Fish and plant production in a recirculating aquaponic system: a new approach to sustainable agriculture in Canada. Acta Hortic. 742, 209-213.

Tyson R.V., Treadwell D.D., Simonne E.H. 2011. Opportunities and challenges to sustainability in aquaponic systems. HorTechnology 21, 6-13. 
Table 1. Harvest biomass (g, mean \pm standard error), sowing date and days to harvest for each cultivar in each treatment are presented. ANOVA $\mathrm{p}$ values are given, with homogeneous groups indicated by the same superscripted letter.

\begin{tabular}{|c|c|c|c|c|c|c|c|}
\hline \multirow[b]{2}{*}{ Cultivar } & \multirow{2}{*}{$\begin{array}{c}\text { Sowing } \\
\text { Date }\end{array}$} & \multicolumn{2}{|c|}{ Days to Harvest } & \multirow{2}{*}{$\begin{array}{c}\text { Low Flow } \\
\left(18.9 \mathrm{~L} \cdot \mathrm{min}^{-1}\right)\end{array}$} & \multirow{2}{*}{$\begin{array}{c}\text { High Flow } \\
\left(75.7 \mathrm{~L}^{\prime} \mathrm{min}^{-1}\right)\end{array}$} & \multirow{2}{*}{$\begin{array}{c}\text { Amended } \\
\left(75.7 \mathrm{~L} \cdot \mathrm{min}^{-1}\right)\end{array}$} & \multirow[b]{2}{*}{ P value } \\
\hline & & Predicted & Actual & & & & \\
\hline \multicolumn{8}{|l|}{ LETTUCE } \\
\hline Bibb 'Rex' & $7 / 18$ & 50 & 49 & $655.0 \pm 110.8^{\mathrm{a}}$ & $1343.8 \pm 69.1^{\mathrm{b}}$ & $869.9 \pm 212.6^{\mathrm{ab}}$ & 0.022 \\
\hline Butterhead 'Rhazes' & $9 / 19$ & 42 & 57 & $189.7 \pm 8.1^{\mathrm{a}}$ & $161.4 \pm 14.6^{\mathrm{a}}$ & $523.3 \pm 17.2^{\mathrm{b}}$ & 0.018 \\
\hline \multicolumn{8}{|l|}{ ASIAN GREENS } \\
\hline Red Rain & $7 / 18$ & $21 / 40$ & 35 & $101.0 \pm 7.0^{\mathrm{a}}$ & $519.8 \pm 17.5^{\mathrm{b}}$ & $423.7 \pm 42.4^{\mathrm{c}}$ & $<0.001$ \\
\hline Mizuna & $7 / 18$ & $21 / 40$ & 35 & $76.2 \pm 9.1^{\mathrm{a}}$ & $620.5 \pm 42.4^{\mathrm{b}}$ & $427.9 \pm 46.1^{\mathrm{c}}$ & $<0.001$ \\
\hline Tokyo Bekana & $7 / 18$ & $21 / 45$ & 35 & $138.1 \pm 18.2^{\mathrm{a}}$ & $927.5 \pm 24.9^{b}$ & $1106.4 \pm 102.7^{\mathrm{b}}$ & $<0.001$ \\
\hline Vitamin Green & $7 / 18$ & $21 / 45$ & 35 & $143.9 \pm 16.3^{\mathrm{a}}$ & $636.1 \pm 49.2^{\mathrm{b}}$ & $894.3 \pm 53.9^{c}$ & $<0.001$ \\
\hline Shungiku & $7 / 18$ & $21 / 45$ & 42 & $71.1 \pm 8.0^{\mathrm{a}}$ & $421.0 \pm 51.3^{\mathrm{b}}$ & $626.3 \pm 84.0^{c}$ & $<0.001$ \\
\hline Tatsoi & $7 / 18$ & $21 / 45$ & 42 & $203.5 \pm 29.9^{\mathrm{a}}$ & $807.7 \pm 73.0^{\mathrm{b}}$ & $977.3 \pm 157.8^{b}$ & 0.001 \\
\hline \multicolumn{8}{|l|}{ MUSTARD GREENS } \\
\hline Suehlihung No. 2 & $9 / 5$ & $21 / 45$ & 49 & $569.3 \pm 25.2^{\mathrm{a}}$ & $1160.7 \pm 138.4^{\mathrm{b}}$ & $1694.7 \pm 108.1^{\mathrm{c}}$ & $<0.001$ \\
\hline Southern Giant Curled & $9 / 5$ & $21 / 45$ & 49 & $396.6 \pm 21.0^{\mathrm{a}}$ & $998.1 \pm 93.4^{\mathrm{b}}$ & $1649.0 \pm 121.6^{\mathrm{c}}$ & $<0.001$ \\
\hline Red Splendor & $9 / 5$ & $21 / 45$ & 49 & $321.6 \pm 25.7^{\mathrm{a}}$ & $920.8 \pm 95.9^{\mathrm{b}}$ & $1157.0 \pm 127.5^{\mathrm{b}}$ & $<0.001$ \\
\hline \multicolumn{8}{|l|}{ OTHER GREENS } \\
\hline Minutina & $7 / 18$ & 50 & 49 & $642.4 \pm 51.3$ & $1123.6 \pm 111.8$ & $857.4 \pm 197.0$ & 0.088 \\
\hline Persian Cress & $10 / 10$ & 21 & 36 & $186.0 \pm 18.1^{\mathrm{a}}$ & $195.3 \pm 16.3^{\mathrm{a}}$ & $257.8 \pm 9.7^{\mathrm{b}}$ & 0.017 \\
\hline Wrinkled Crinkled Cress & $10 / 10$ & 30 & 36 & $93.3 \pm 7.1^{\mathrm{a}}$ & $82.2 \pm 2.5^{\mathrm{a}}$ & $138.0 \pm 3.4^{\mathrm{b}}$ & $<0.001$ \\
\hline Arugula & $8 / 29$ & $21 / 40$ & 56 & $89.3 \pm 9.0^{\mathrm{a}}$ & $869.6 \pm 63.6^{\mathrm{b}}$ & $1095.4 \pm 35.1^{\mathrm{c}}$ & 0.007 \\
\hline Surrey & $8 / 29$ & $21 / 40$ & 56 & $81.9 \pm 4.5^{\mathrm{a}}$ & $513.9 \pm 35.0^{\mathrm{b}}$ & $568.6 \pm 130.1^{\mathrm{b}}$ & 0.023 \\
\hline Sylvetta & $8 / 29$ & 50 & 56 & $26.1 \pm 5.7^{\mathrm{a}}$ & $106.7 \pm 13.6^{\mathrm{b}}$ & $58.0 \pm 12.7^{\mathrm{a}}$ & 0.002 \\
\hline Italian Dandelion 'Clio' & $8 / 26$ & 48 & 73 & $29.5 \pm 6.3^{\mathrm{a}}$ & $44.3 \pm 9.4^{\mathrm{a}}$ & $471.5 \pm 33.4^{\mathrm{b}}$ & $<0.001$ \\
\hline \multicolumn{8}{|l|}{ VEGETABLES } \\
\hline Kolrabi 'Winner' & $7 / 18$ & 45 & 70 & $1015.7 \pm 68.8^{\mathrm{a}}$ & $2016.2 \pm 151.5^{\mathrm{b}}$ & $1154.2 \pm 202.8^{\mathrm{a}}$ & 0.002 \\
\hline Swiss Chard 'Peppermint' & $9 / 30$ & $33 / 60$ & 46 & $12.8 \pm 2.5$ & $5.7 \pm 2.0$ & $11.6 \pm 1.6$ & 0.079 \\
\hline Beet 'Early Wonder Tall Top' & $9 / 30$ & 45 & 46 & $15.3 \pm 4.7^{\mathrm{a}}$ & $10.7 \pm 2.2^{\mathrm{a}}$ & $52.6 \pm 5.8^{\mathrm{b}}$ & $<0.001$ \\
\hline Beet 'Bulls Blood' & $9 / 30$ & 35 & 46 & $6.2 \pm 0.4^{\mathrm{a}}$ & $3.4 \pm 0.4^{\mathrm{a}}$ & $29.5 \pm 2.7^{\mathrm{b}}$ & 0.007 \\
\hline \multicolumn{8}{|l|}{ HERBS* } \\
\hline Sorrel $(\mathrm{P})$ & $7 / 18$ & 35 & 42 & $334.7 \pm 33.0^{\mathrm{a}}$ & $622.4 \pm 58.9^{\mathrm{b}}$ & $504.7 \pm 77.1^{\mathrm{ab}}$ & 0.022 \\
\hline Green Shiso (A) & $7 / 18$ & 60 & 49 & $143.5 \pm 14.3^{\mathrm{a}}$ & $115.1 \pm 24.0^{\mathrm{a}}$ & $217.6 \pm 59.8^{b}$ & $<0.001$ \\
\hline
\end{tabular}




\begin{tabular}{lccccccc} 
Cilantro (A) & $7 / 18$ & 85 & 63 & $1012.4 \pm 219.3$ & $888.4 \pm 78.2$ & $781.5 \pm 168.5$ & 0.631 \\
Oregano (P) & $7 / 18$ & 55 & 70 & $47.5 \pm 8.7$ & $93.6 \pm 9.5$ & $66.6 \pm 27.3$ & 0.225 \\
Lovage (P) & $7 / 18$ & 90 & 74 & $496.2 \pm 60.5^{\mathrm{a}}$ & $569.4 \pm 45.1^{\mathrm{a}}$ & $207.2 \pm 22.3^{\mathrm{b}}$ & $<0.001$ \\
Chive (P) & $7 / 18$ & 90 & 84 & $130.2 \pm 19.0^{\mathrm{a}}$ & $138.9 \pm 20.8^{\mathrm{a}}$ & $638.1 \pm 140.7^{\mathrm{b}}$ & 0.024 \\
Parsley (B) & $7 / 18$ & 80 & 112 & $116.8 \pm 46.2$ & $244.4 \pm 99.3$ & $370.5 \pm 233.2$ & 0.51 \\
Salad Burnet (P) & $8 / 26$ & 75 & 73 & $600.9 \pm 76.7$ & $957.1 \pm 179.2$ & $1084.0 \pm 115.1$ & 0.068 \\
Winter Savory (P) & $8 / 26$ & 70 & 81 & $32.1 \pm 5.4^{\mathrm{a}}$ & $47.0 \pm 8.7^{\mathrm{a}}$ & $120.5 \pm 20.2^{\mathrm{b}}$ & 0.018 \\
Rosemary (P) & $8 / 26$ & 100 & 81 & $3.4 \pm 0.9^{\mathrm{a}}$ & $4.9 \pm 0.7^{\mathrm{a}}$ & $13.2 \pm 2.4^{\mathrm{b}}$ & 0.006 \\
\hline
\end{tabular}

* Plant type (annual (A), perennial (P) or biennial (B) is denoted for the herbs. 


\section{Figure Captions}

Figure 1. Mean, maximum and minimum air temperatures $\left({ }^{\circ} \mathrm{C}\right)$ in the high tunnel are presented. The record is incomplete due to technical difficulties with the temperature logger. The record is supplemented with maximum and minimum air temperatures recorded $450 \mathrm{~m}$ away at a NOAA observation point.

Figure 2. Schematic of experimental layout depicting the three channels (not to scale). One channel received low flow $(18.9 \mathrm{~L} / \mathrm{min})$ of aquaculture effluent, one received high flow $(75.7$ $\mathrm{L} / \mathrm{min}$ ) and the third received high flow $(75.7 \mathrm{~L} / \mathrm{min})$ and the growing medium was amended with composted fish waste. Each channel contained 17 rows of Speedling trays. Each row consisted of 4 trays and was planted in a single cultivar. The rows of trays were arranged so that each cultivar was in the same position within the channel (depicted by the shaded row).

Figure 3. Stand establishment (percent filled cells per tray). Means \pm standard error for each cultivar are reported.

Figure 4. Individual biomass $(\mathrm{g})$. Means ( \pm standard error) computed from each of the tray means are reported for each cultivar. Individual biomass is a fresh weight.

Figure 5. Inorganic nutrient (ammonium, nitrate and phosphate) concentrations $\left(\mathrm{mg} \cdot \mathrm{L}^{-1}\right.$, mean \pm standard error) at the outlet of each channel. Influent concentration is indicated by the dotted line. Total suspended solids concentrations $\left(\mathrm{mg} \cdot \mathrm{L}^{-1}\right.$, mean \pm standard error) at the channel influents and the outlets are presented. 
Figure 1

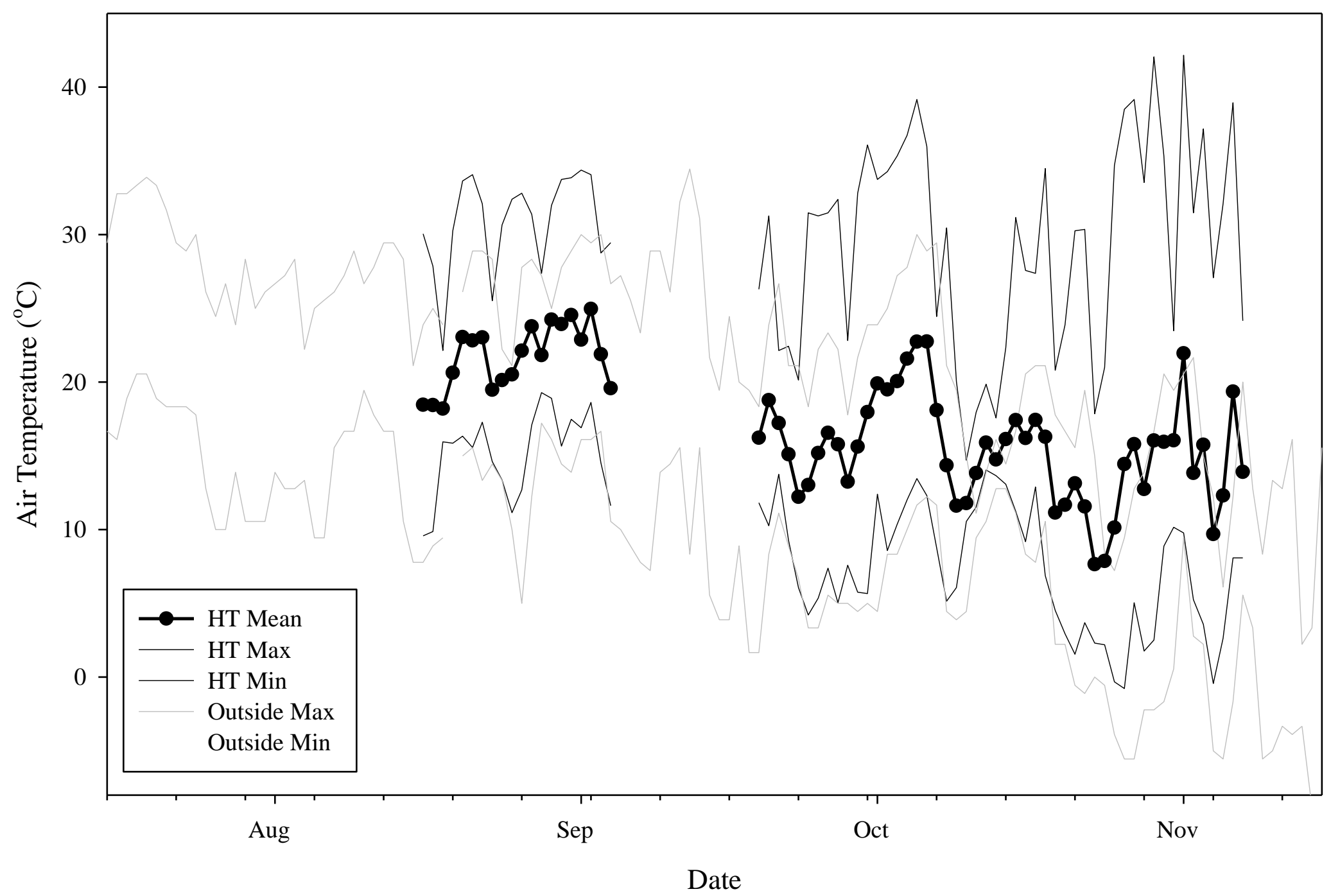


Figure 2

Low Flow (18.9 L/min)

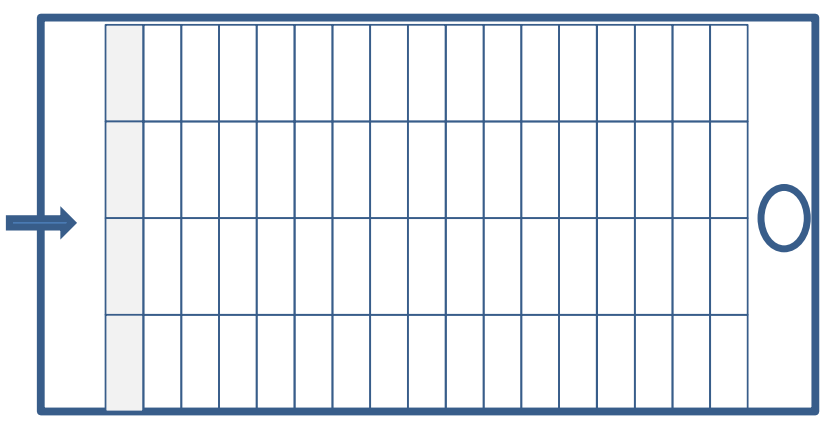

High Flow (75.7 L/min)

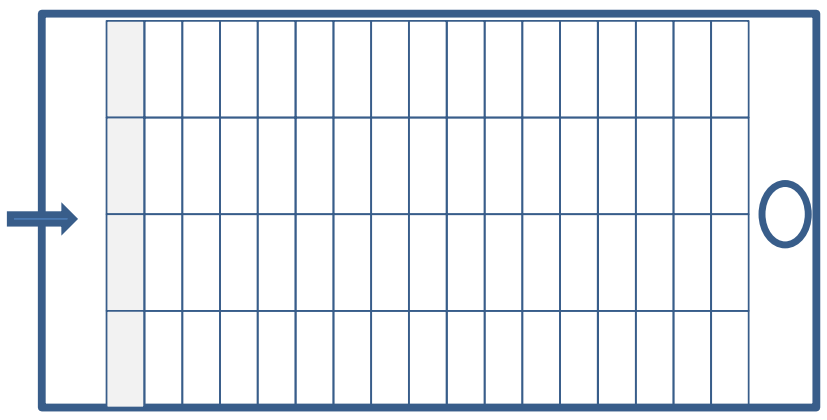

Amended High Flow (75.7 L/min)

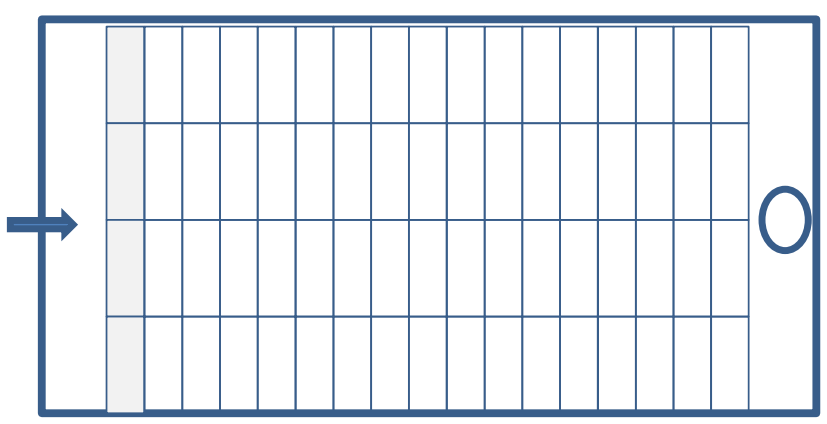




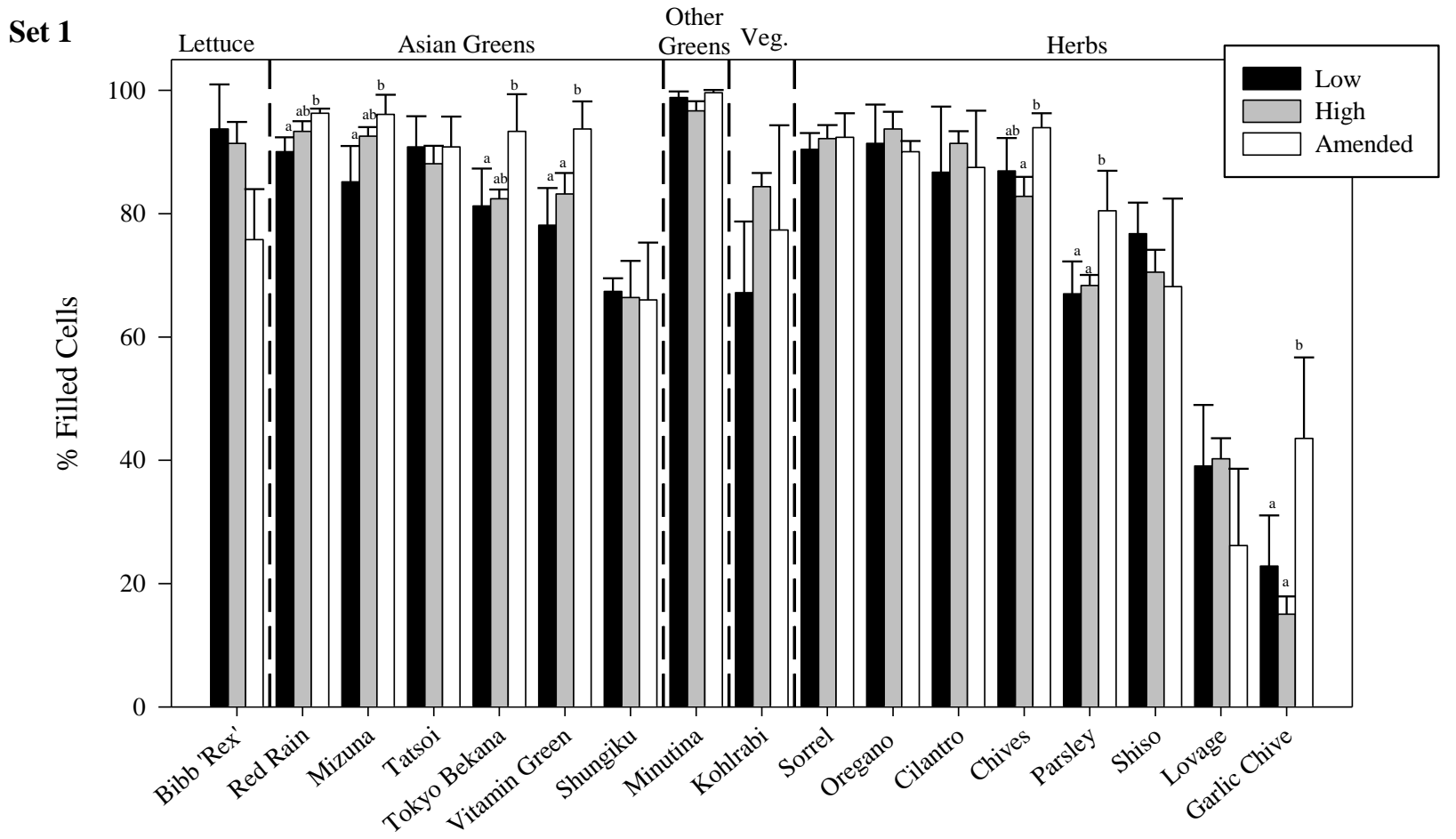

Set 2

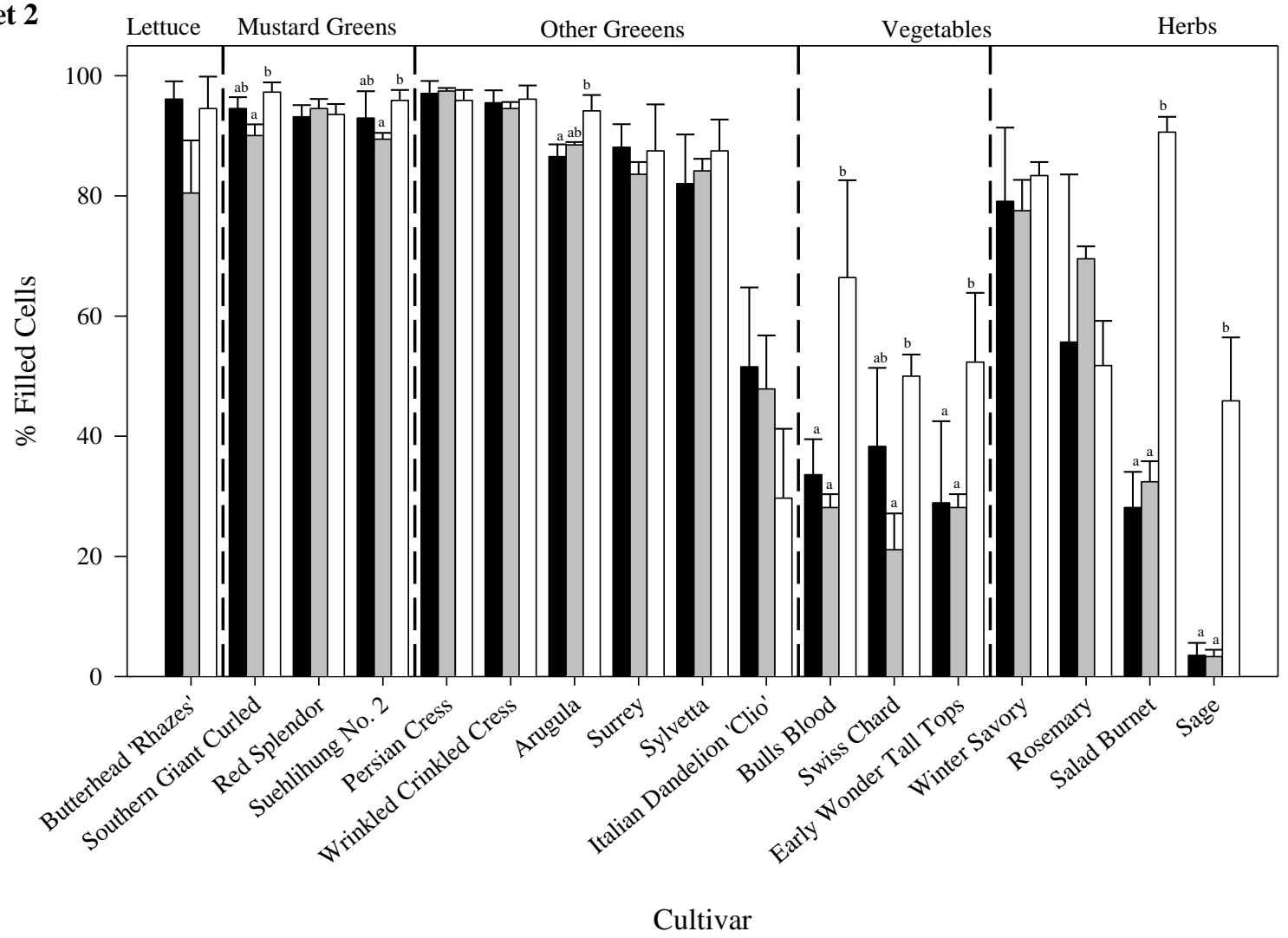


Figure 4
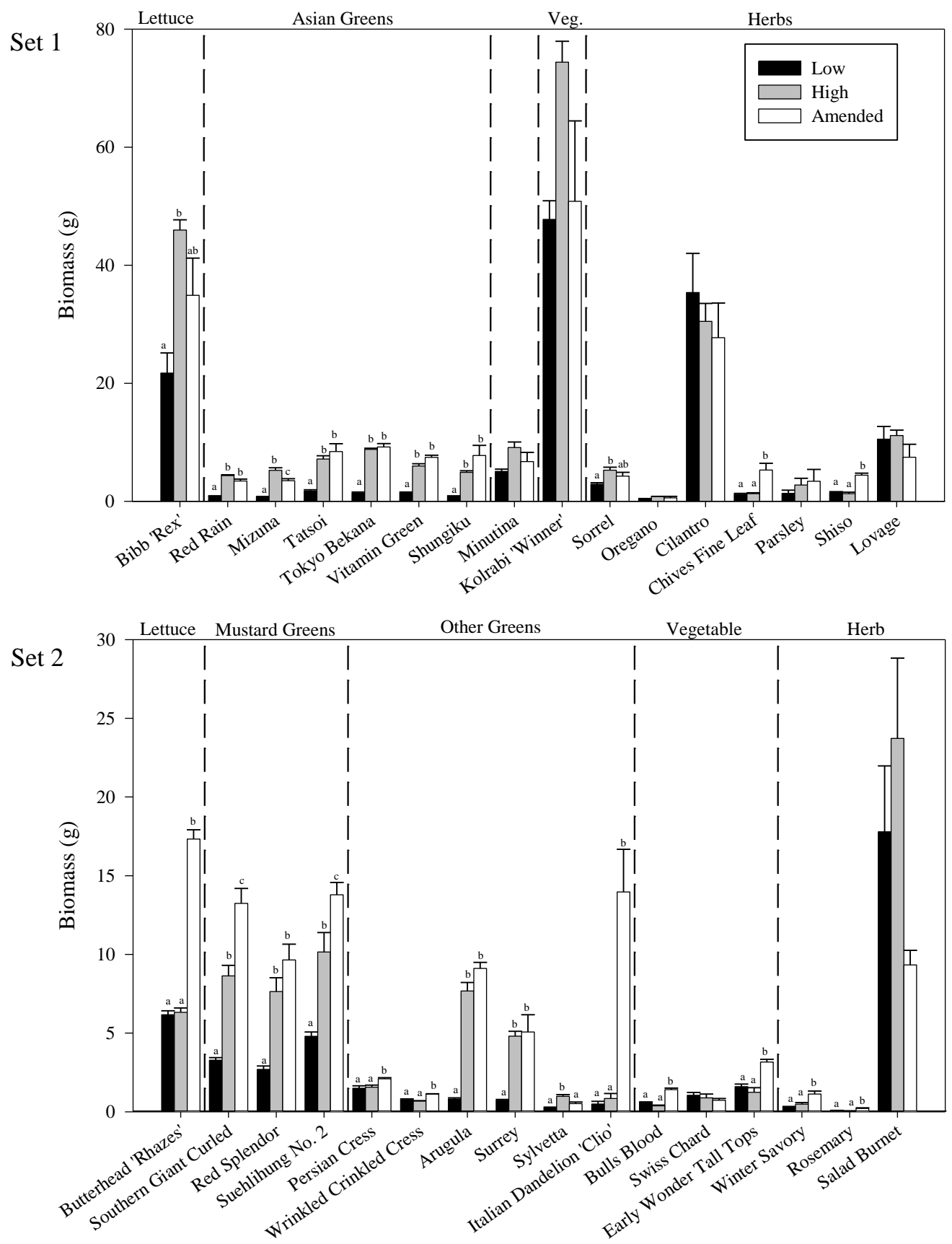

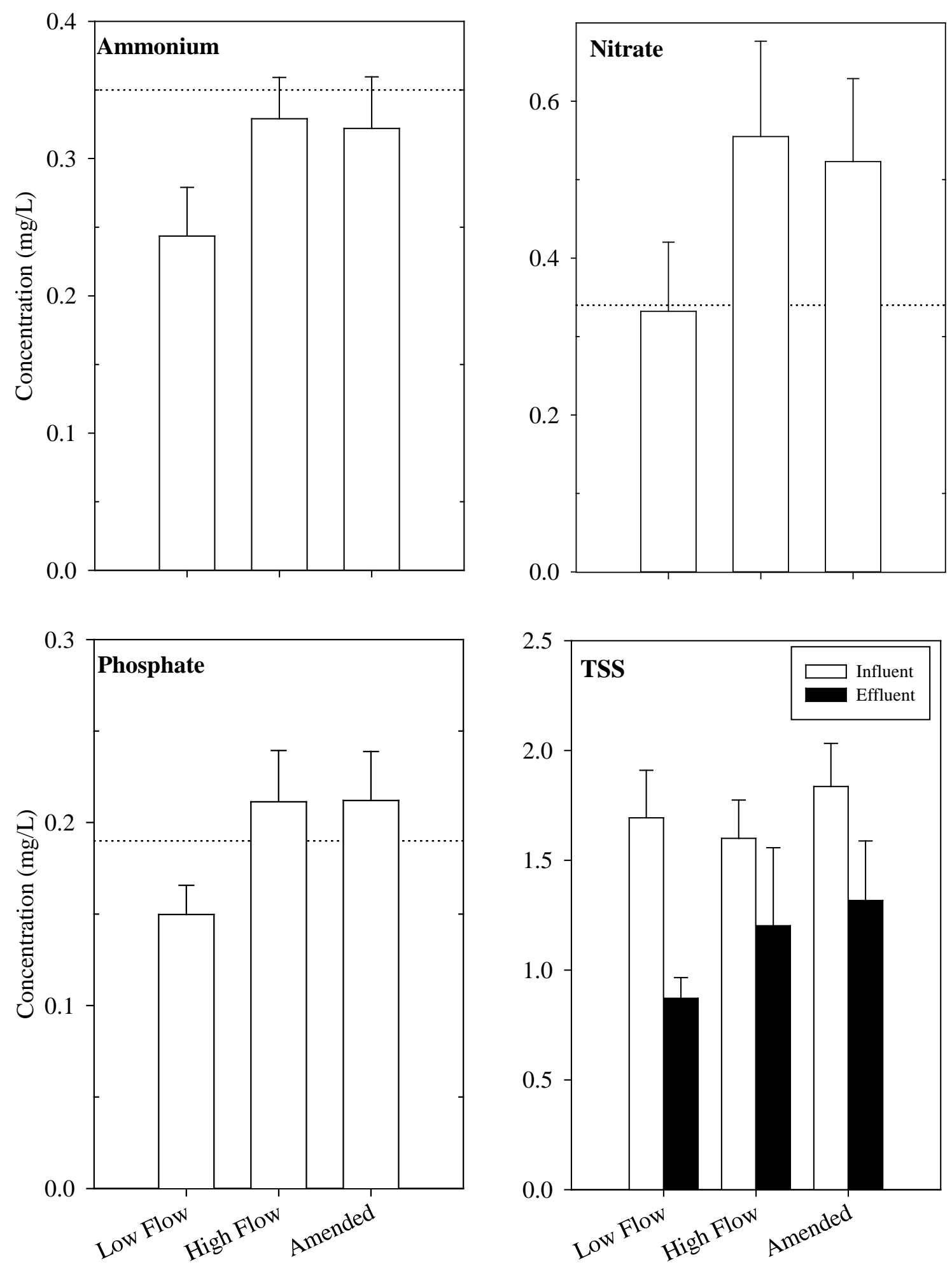

Treatment

Treatment 